\title{
Parálisis fláccida aguda por enterovirus con resolución completa del cuadro neurológico. A propósito de un caso pediátrico
} Acute flaccid paralysis related to enterovirus with complete resolution of the neurological symptoms. A pediatric case report

\author{
Dra. Agustina Teves Echazúa ${ }^{a}$ Dr. Javier A. Fain ${ }^{a}$, Dr. Rodolfo P. Moreno ${ }^{a}$, Dr. Alberto Hernándeza, \\ Dra. Patricia G. Topp ${ }^{a}$ Dra. Liliana Vázquez $z^{b}$ Dr. Gustavo Cardigni ${ }^{a}$
}

\section{RESUMEN}

Desde la eliminación de la circulación del virus polio salvaje, disminuyeron los casos de parálisis fláccida aguda. Sin embargo, continúan ocurriendo casos asociados a otros enterovirus no polio y virus neurotropos. Se presenta el caso de una paciente de 9 años con diagnóstico de meningitis y mielitis con compromiso motor en los miembros inferiores y vejiga neurogénica asociado a enterovirus, con resolución completa del cuadro neurológico posterior a la administración de gammaglobulina hiperinmune. Palabras clave: parálisis fláccida aguda, mielitis, enterovirus, gammaglobulina.

\section{ABSTRACT}

Since the wild poliovirus no longer circulates, the number of cases of acute flaccid paralysis decreased. However, cases related to non-polio enteroviruses and neurotrope viruses continue to occur. We present a nine-year-old patient with meningitis and myelitis with motor involvement in the lower limbs and neurogenic bladder associated with enterovirus, with complete resolution of the neurological symptoms following the administration of hyperimmune gammaglobulin.

Key words: acute flaccid paralysis, myelitis, enterovirus, gammaglobulins.

http: / / dx.doi.org/ 10.5546/ aap.2019.e664

Cómo citar: Teves Echazú A, Fain JA, Moreno RP, Hernández A, et al. Parálisis fláccida aguda por enterovirus con resolución completa del cuadro neurológico. A propósito de un caso pediátrico. Arch Argent Pediatr 2019;117(6):e664-e669.

a. Servicio de Pediatría, Sanatorio de la Trinidad Palermo, Buenos Aires, Argentina.

b. Servicio de Infectología Pediátrica, Sanatorio de la Trinidad Palermo, Buenos Aires, Argentina.

Correspondencia:

Dra. Agustina Teves Echazú: agustinatevesechazu@gmail.com

Financiamiento: Ninguno.

Conflicto de intereses: Ninguno que declarar.

Recibido: 29-12-2018

Aceptado: 25-6-2019

\section{INTRODUCCIÓN}

La incidencia de parálisis fláccida aguda (PFA) disminuyó drásticamente desde la aplicación universal de las vacunas contra la poliomielitis. ${ }^{1}$ En 1994, la Organización Mundial de la Salud declaró a América libre de polio salvaje ${ }^{1}$ (existen reportes secundarios al virus polio vacunal en Venezuela en 2018). ${ }^{2}$ Sin embargo, continúan ocurriendo casos secundarios a otros enterovirus y virus neurotropos. Las infecciones por enterovirus, habitualmente, causan cuadros banales, pero estos pueden ser graves (como encefalitis, miocarditis, PFA, etc.) y dejar secuelas o ser mortales. ${ }^{3}$

En Estados Unidos, en 2014, aumentaron los casos de cuadros respiratorios graves y PFA, con identificación de enterovirus D68 en secreciones nasofaríngeas. ${ }^{4}$ La mayoría de los casos de mielitis asociadas a enterovirus evolucionan con secuelas neurológicas. ${ }^{5}$

Se presenta a una paciente con meningitis y PFA por enterovirus con resolución completa de su signo-sintomatología neurológica.

\section{CASO CLÍNICO}

Paciente de 9 años, previamente sana, con vacunas completas, que consultó por vómitos, dolor abdominal y fiebre de 4 días de evolución. La semana previa había padecido un cuadro de rinorrea tratado con medicación sintomática.

Al momento del examen físico, se constató regular estado general, fiebre, dolor abdominal inespecífico y, con un sedimento urinario patológico, se consideró pielonefritis y se internó por intolerancia oral. El análisis de laboratorio presentó leucocitosis con neutrofilia, reactantes de fase aguda elevados, función hepática y renal con valores normales para la edad. Por presentar cefalea y rigidez de la nuca, se sospechó síndrome meníngeo y se realizó una tomografía axial computada (TAC) de cerebro y una punción lumbar (PL). La TAC arrojó como único dato relevante pansinusopatía. 
El líquido cefalorraquídeo (LCR) presentó 115 elementos (el $95 \%$, monomorfonuclear), con glucorraquia y proteinorraquia normales. Se medicó con ceftriaxona por 10 días. Los hemocultivos, el urocultivo y el LCR (gérmenes comunes, hongos y micobacterias) fueron negativos. El coprocultivo presentaba flora habitual. La reacción en cadena de la polimerasa (polymerase chain reaction; PCR, por sus siglas en inglés) para enterovirus y virus del herpes en el LCR resultó negativa.
La paciente persistió febril, con cefalea y rigidez de la nuca, por lo que se solicitó una resonancia magnética nuclear (RMN) del cerebro, que resultó compatible con un proceso inflamatorio meníngeo de probable etiología infecciosa y pansinusopatía.

Al $5^{\circ}$ día, se agregó debilidad de los miembros inferiores, alteración de la marcha y retención urinaria. Al momento del examen neurológico, se encontraba vigil, orientada, con lenguaje conservado, con los pares craneales sin

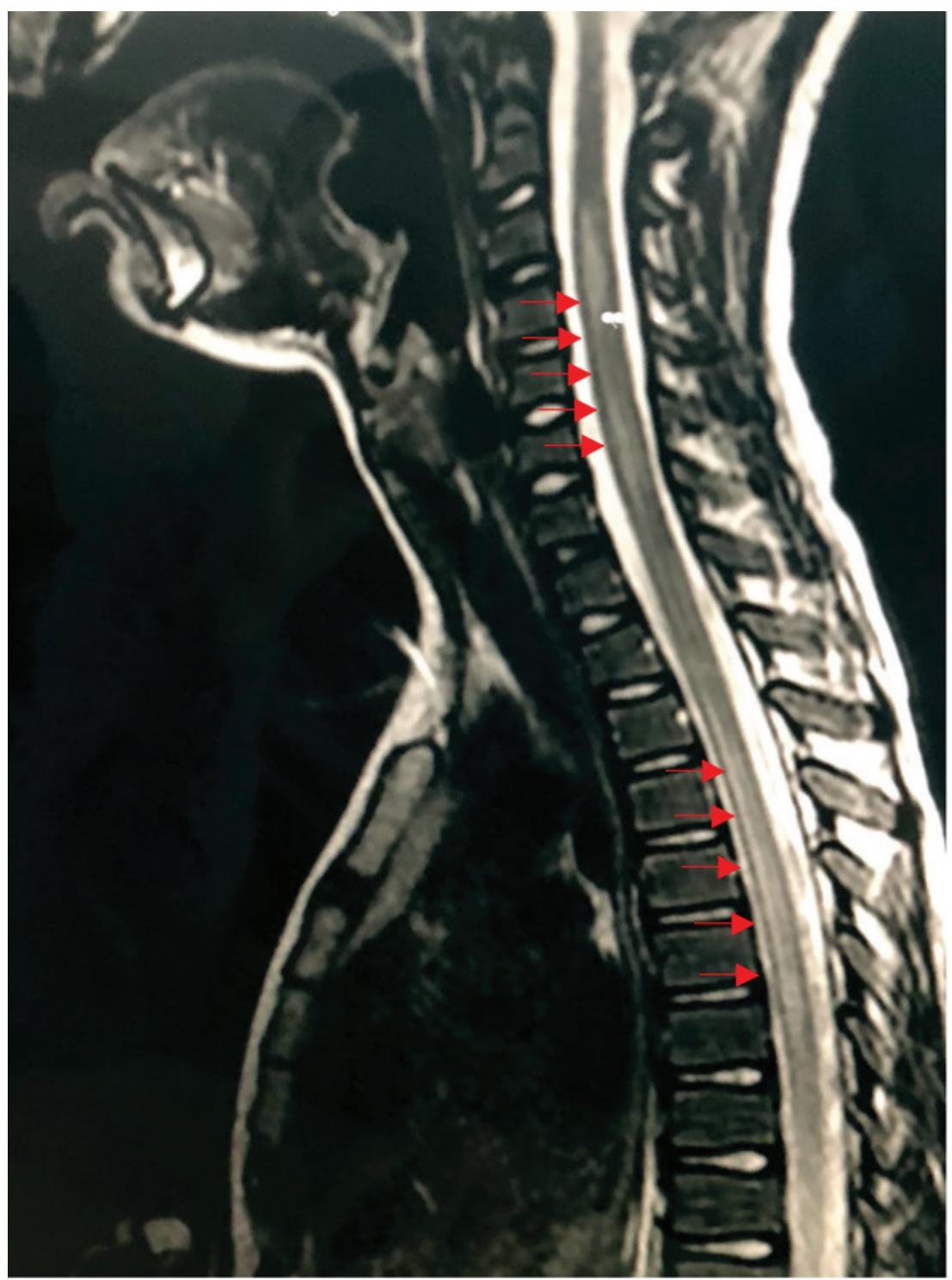


alteraciones; la fuerza en los miembros superiores estaba conservada, $y$, en los miembros inferiores, era de 2/5; hiperalgesia en los miembros inferiores sin constatarse nivel sensitivo evidente; taxia acorde al foco motor, reflejos osteotendinosos en los miembros superiores de $2 / 4 \mathrm{y}$, en los miembros inferiores, de $1 / 4$, simétricos; sin Hoffman, reflejo plantar flexor bilateral; rigidez de la nuca solo con la fiebre. Se evidenció globo vesical, y presentó diuresis luego de la colocación de una sonda vesical.

Se realizó una RMN de la columna, que informó una señal hiperintensa en C3-C7 y D3-D11, sin refuerzo con contraste endovenoso, compatible con mielopatía (Figuras 1,2,3). Resultó llamativo que, a pesar de presentar compromiso medular cervical, no se evidenciaron alteraciones en los miembros superiores.

Con estos hallazgos, se consideró el cuadro como mielitis de probable etiología infecciosa, por lo cual se decidió ampliar la búsqueda etiológica. Se realizó una nueva PL, con citoquímico con disminución del recuento celular (15 leucocitos $/ \mathrm{mm}^{3}$, con predominio mononuclear), proteinorraquia y glucorraquia normales. Se realizó PCR múltiple (Film Array ${ }^{\circledR}$ ), que resultó negativa para E. coli K1, Haemophilus influenzae, Listeria monocytogenes, Neisseria

FIgURA 2. Resonancia magnética nuclear de la columna cervical: corte axial que muestra una señal hiperintensa sin refuerzo de contraste endovenoso

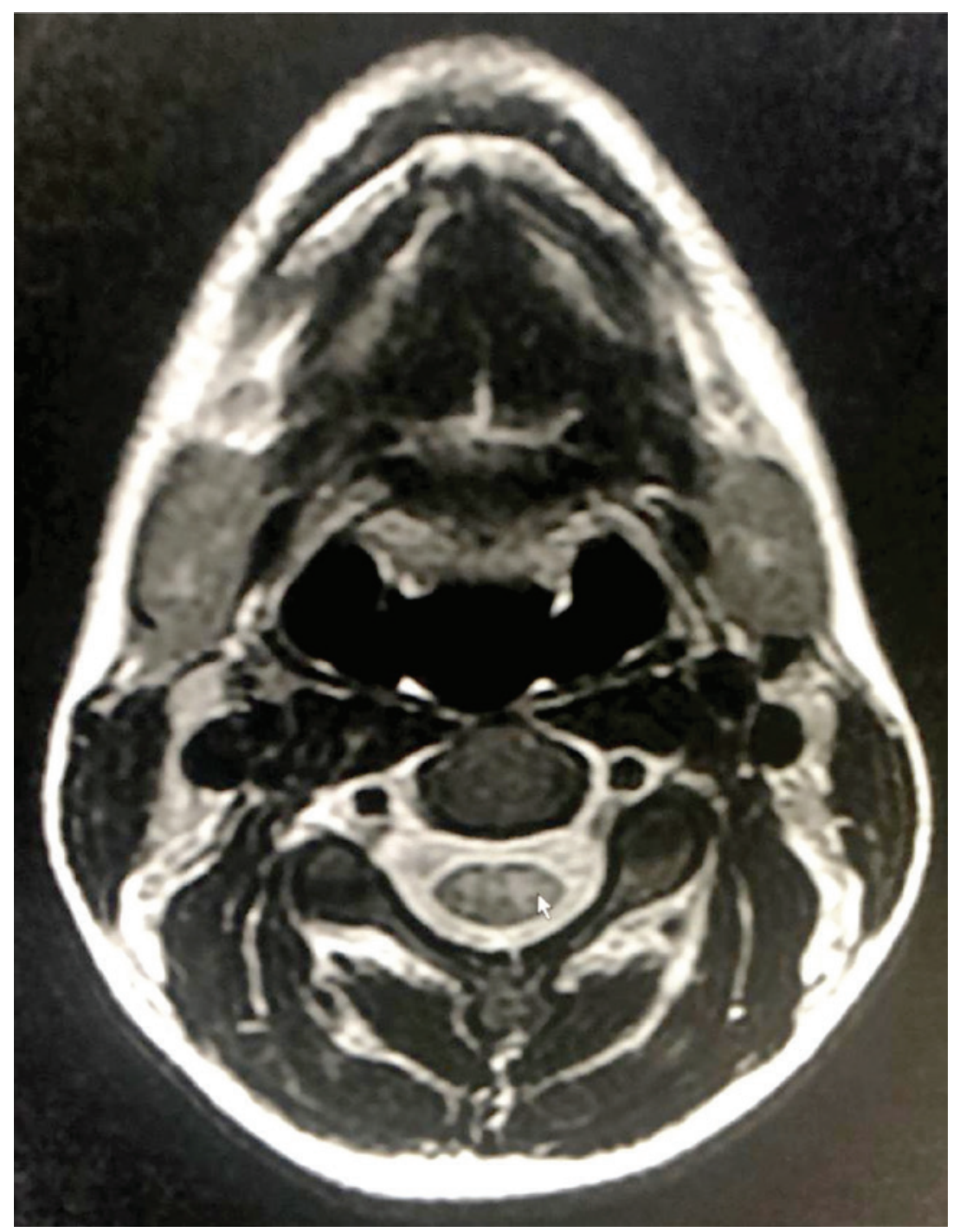


meningitidis, Streptococcus agalactiae, Streptococcus pneumoniae, citomegalovirus, enterovirus, virus del herpes simple tipo 1, 2 y 6, Parechovirus, varicela zóster, Cryptococcus neoformans y gattii. Se enviaron muestras para neurovirus en el LCR, materia fecal y secreciones nasofaríngeas al Servicio de Neurovirus del Instituto Nacional de Microbiología “Dr. Carlos G. Malbrán”, y se encontró positiva la $P C R$ para enterovirus en secreciones nasofaríngeas, que se tipificó como Rhinovirus.

$\mathrm{Al} 6^{\circ}$ día de internación, por continuar febril, sin mejoría de la sintomatología neurológica y, a pesar de no existir recomendaciones categóricas en relación con el uso de gammaglobulina, se decidió administrarla en dosis de $2 \mathrm{~g} / \mathrm{kg}$. Al día siguiente, por primera vez desde su internación, se mantuvo afebril por 48 horas.

Por continuar la clínica neurológica y recrudecer la fiebre, nuevamente, se indicó los días $13^{\circ}$ y $14^{\circ}$; presentó otra defervescencia y, de manera gradual, comenzó a recuperar la fuerza muscular y, por último, la micción espontánea.

Durante la internación, se realizaron fondo de ojos (normal), factor antinuclear (negativo), prueba cutánea de derivado proteico purificado (purified protein derivative; PPD, por sus siglas en inglés) (negativa), evaluación por hematología (frotis normal). No se realizó un electromiograma.
Se repitió, antes del alta, una RMN de la columna, y no se observaron lesiones en la médula espinal (Figura 4). Fue dada de alta al $25^{\circ}$ día de internación sin secuelas neurológicas. Continuó con controles con el pediatra de cabecera y Neurología. Actualmente, se encuentra asintomática y reinició la escolaridad y la actividad física.

\section{DISCUSIÓN}

Desde 2014, se han reportado brotes de PFA en diversas regiones. En nuestro país, se registraron, en 2016, 23 casos de mielitis fláccida aguda, y, en 12 de ellos, se detectó enterovirus D68. En 2017, solo se diagnosticó un caso de mielitis aguda; en 2018, se registraron 3 casos de mielitis aguda fláccida y, en ninguno, se aisló enterovirus D68. ${ }^{6} \mathrm{Si}$ bien, en las estadísticas oficiales del Ministerio de Salud, no se hace una mención especial al Rhinovirus, en el apartado referente a PFA, existen reportes de series de casos en los cuales se describen pacientes que presentaron aislamiento de este germen. ${ }^{5}$

Tradicionalmente, el diagnóstico de enterovirus (herpangina o enfermedad bocamano-pie) era un elemento tranquilizador en la meningoencefalitis aséptica dado su habitual buen pronóstico. Esta visión cambió luego de varias epidemias por enterovirus con elevada morbimortalidad. Existen más de 100 serotipos,

FIgURA 3. Resonancia magnética nuclear de la columna cervical: corte axial que muestra una señal hiperintensa sin refuerzo de contraste endovenoso

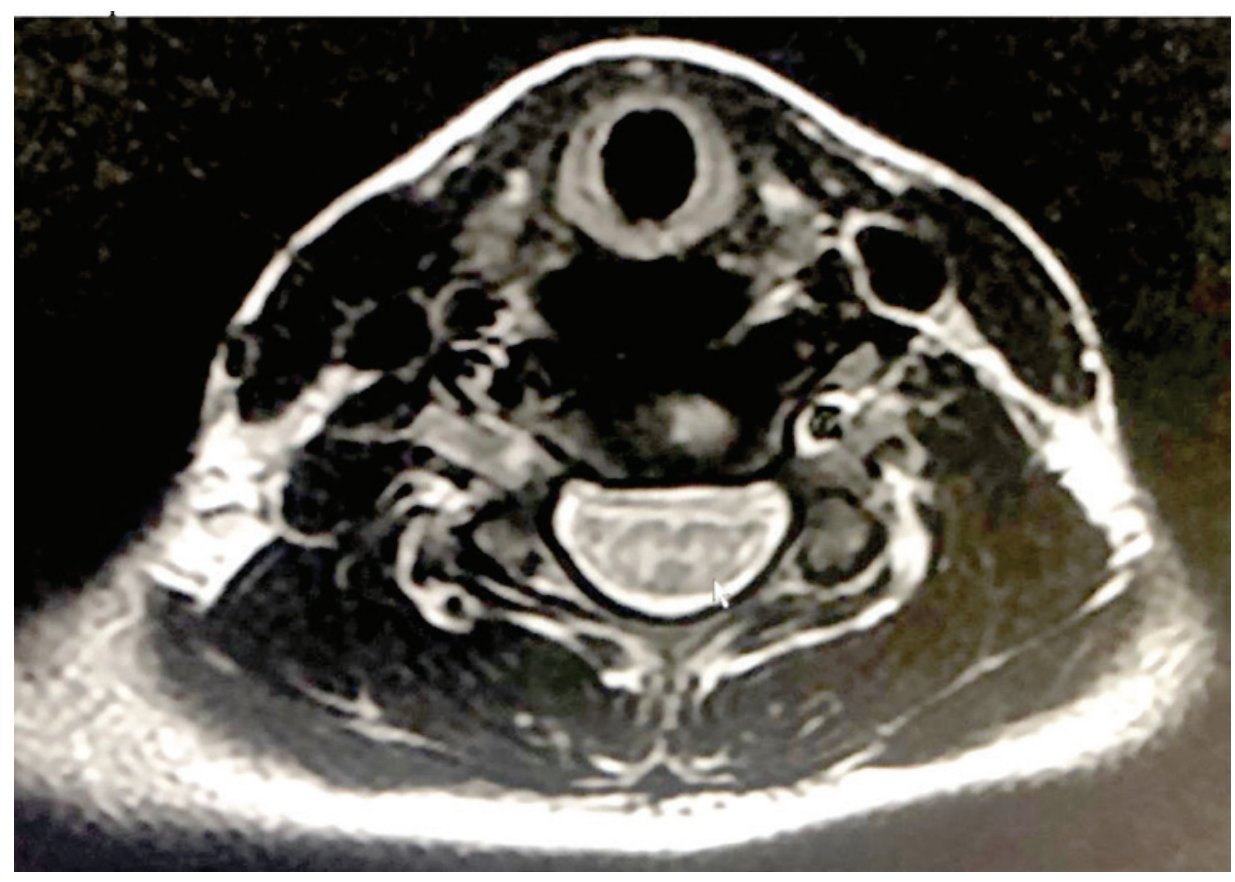


que pueden causar complicaciones neurológicas. Los dos protagonistas que alarman a nivel mundial son A71 y D68.

La mayoría de los casos tienen como antecedente una infección respiratoria aguda en los diez días previos al inicio de la sintomatología neurológica y presentan fiebre al momento de la admisión. ${ }^{5}$ La manifestación clínica más frecuente es la debilidad de uno o más miembros que evoluciona a la PFA con arreflexia. ${ }^{3,5,7,8}$ Está descrita la retención urinaria como presentó nuestra paciente. ${ }^{5}$ La pleocitosis en el LCR con predominio linfocitario es frecuente. ${ }^{3}$
La RMN muestra lesiones características: afectación selectiva de sustancia gris, con imágenes hiperintensas en T2 y FLAIR que no se refuerzan con contraste endovenoso y afectación medular en distintos niveles con extensión en forma longitudinal. El cono medular y la cola de caballo se encuentran frecuentemente afectados. $^{8}$

No hay un tratamiento específico para las PFA asociadas al enterovirus. La mayoría de los pacientes han sido tratados con inmunoglobulina, pulsos de esteroides, plasmaféresis o una combinación de todos. ${ }^{9,10}$

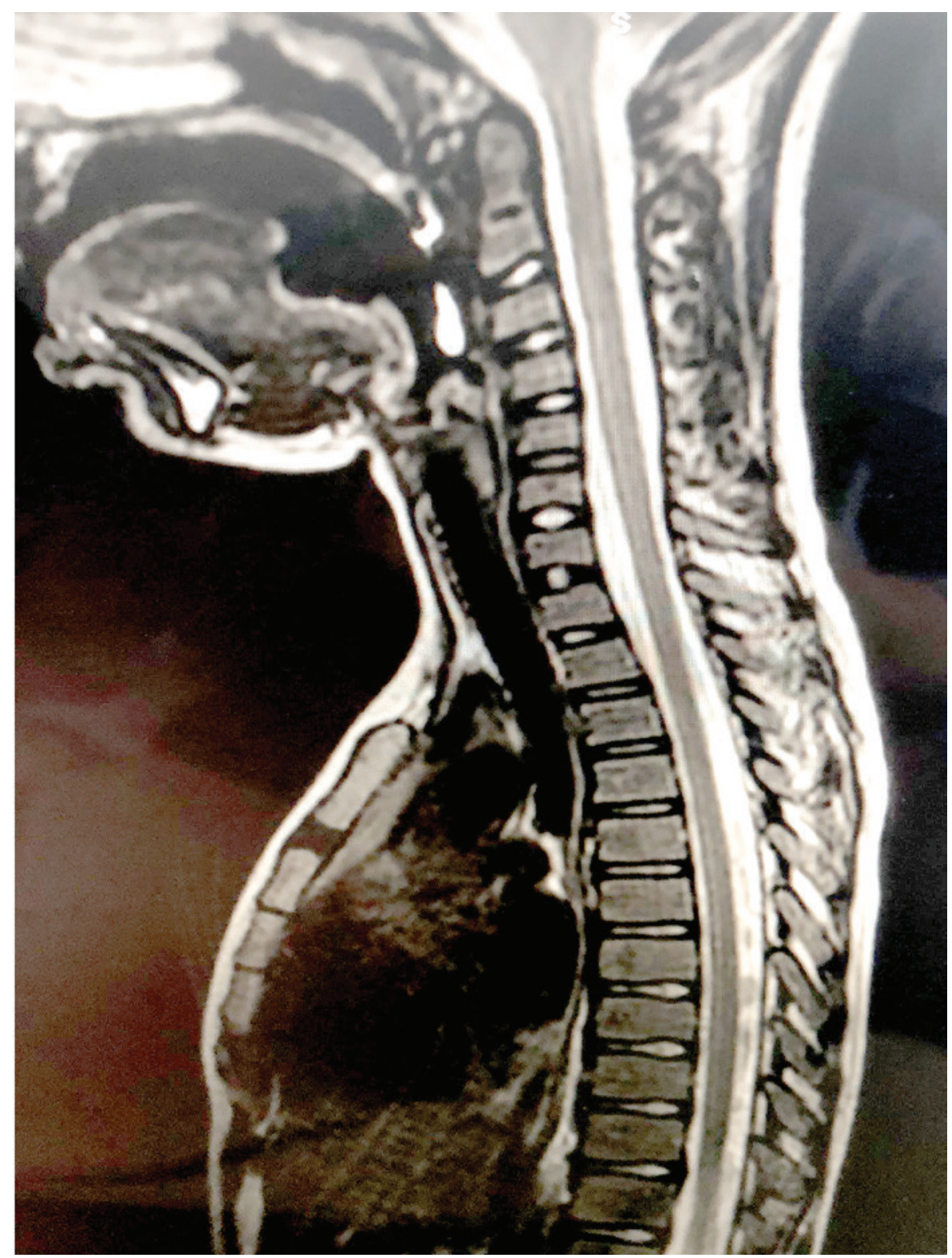


La gammaglobulina no está recomendada de forma habitual. ${ }^{11}$ Podría ejercer cierto beneficio al aportar anticuerpos neutralizantes, disminuir la descarga simpática y atenuar la producción de citoquinas. ${ }^{12}$ En nuestra paciente, se administró en dos oportunidades, con franca mejoría de la curva febril en ambas ocasiones y mejoría del déficit neurológico posterior al segundo ciclo.

El informe de los Centers for Disease Control and Prevention (CDC) sobre el manejo de la PFA enfatiza en que no hay datos basados en ensayos clínicos en cuanto a las intervenciones terapéuticas enumeradas. ${ }^{13}$ La mayoría de los pacientes descritos en la literatura no recuperan las funciones neurológicas completamente, a diferencia de lo ocurrido en el caso presentado. ${ }^{5,14}$

Como se mencionó antes, existen reportes de casos de PFA en los cuales se aisló Rhinovirus, ${ }^{5}$ sin embargo, en ellos, no se analiza en forma particular la evolución de estos pacientes. Se considera que el aislamiento de este germen puede estar asociado a una evolución más benigna que los enterovirus D68 y A 71, lo que puede ser una explicación para la llamativa recuperación que tuvo la paciente presentada. Al ser una asociación poco frecuente, es difícil poder establecer un patrón típico de evolución de la PFA asociada a este germen en particular.

Se considera importante presentar este caso, que se suma a los casos ocurridos en nuestro país, para la detección precoz, que permita un mejor abordaje inicial y tratamiento de soporte.

\section{REFERENCIAS}

1. Organización Panamericana de la Salud, Organización Mundial de la Salud. Las Américas cumplen 25 años sin polio. 2016. [Acceso: 30 de julio de 2018]. Disponible en: https: / / www.paho.org/hq/index.php?option=com_cont ent\&view=article\&id=12640:americas-celebrate-25-yearswithout-polio\&Itemid=1926\&lang=es.

2. Organización Panamericana de la Salud, Organización Mundial de la Salud. Actualización epidemiológica. Detección de poliovirus vacunal, Sabin tipo 3, en un caso de parálisis fláccida aguda. 2018. [Acceso: octubre de
2018]. Disponible en: https://www.paho.org/hq/index. php?option $=$ com_docman\&view $=$ download\&category_ slug $=$ poliomelitis-3100\&alias $=45363-8$-junio-2018actualizacion-epidemiologica-deteccion-poliovirusvacunal-sabin-tipo-3-un-caso-paralisis-flacida-aguda$363 \&$ Itemid $=270 \&$ lang $=e$.

3. Leal Barceló AM, Carrascosa García P, Rincón López EM, Miranda Herrero MC, et al. Brote de infección por enterovirus causantes de afectación neurológica grave en un hospital terciario. An Pediatr (Barc). 2018; 89(6):378-81.

4. Greninger AL, NaccacheSN, Messacar K, Clayton A, etal. A novel outbreak enterovirus D68 strain associated with acute flaccid myelitis cases in the USA (2012-14): a retrospective cohort study. Lancet Infect Dis. 2015; 15(6):671-82.

5. Pérez MG, Rosanova MT, Freire MC, Paz MI, et al. Aumento inusual de casos de mielitis en un hospital pediátrico en Argentina. Arch Argent Pediatr. 2017;115(4):364-9.

6. Informe especial: Mielitis Aguda Fláccida asociadas a Enterovirus D68 en el marco dela vigilancia epidemiológica deParálisis Agudas Fláccidas en Argentina. Boletín integrado de vigilancia. 2019; 446(SE 13):34-40.

7. Teoh HL, Mohammad SS, Britton PN, Kandula T, et al. Clinical characteristics and functional motor outcomes of enterovirus 71 neurological disease in children. JAMA Neurol. 2016; 73(3):300-7.

8. Maloney JA, Mirsky DM, Messacar K, Dominguez SR, et al. MRI findings in children with acute flaccid paralysis and cranial nerve dysfunction occurring during the 2014 enterovirus D68 outbreak. AJNR Am J Neuroradiol. 2015; 36(2):245-50.

9. Nelson GR, Bonkowsky JL, Doll E, Green M, et al. Recognition and management of acute flaccid myelitis in children. Pediatr Neurol. 2016; 55:17-21.

10. Esposito S, Chidini G, Cinnante C, Napolitano N, et al. Acute flaccid myelitis associated with enterovirus-D68 infection in an otherwise healthy child. Virol J. 2017;14(1):4.

11. Centers for Disease Control and Prevention. Enterovirus D68. 2018. [Acceso: julio de 2019]. Disponible en: https: / / www.cdc.gov/non-polio-enterovirus/about/ev-d68.html.

12. Casas-Alba D, De Sevilla MF, Valero-Rello A, Fortuny C, et al. Outbreak of brainstem encephalitis associated with enterovirus-A71 in Catalonia, Spain (2016): A clinical observational study in a children's reference centre in Catalonia. Clin Microbiol Infect. 2017; 23(11):874-81.

13. Centers for Disease Control and Prevention. Acute flaccid myelitis: interim considerations for clinical management; 2014. [Acceso: agosto de 2017]. Disponible en: https:// www.cdc.gov/acute-flaccid-myelitis / downloads / interim-considerations-afm.pdf.

14. Yoder JA, Lloyd M, Zabrocki L, Auten J. Pediatric acute flaccid paralysis: enterovirus D68-associated anterior myelitis. J Emerg Med. 2017; 53(1):e19-23. 